\title{
Creation and Characterization of a Double Null Puroindoline Genotype in Spring Wheat
}

\author{
John M. Martin,${ }^{\dagger}$ Andrew C. Hogg, Richard W. Webster, and Michael J. Giroux
}

\section{ABSTRACT}

Wheat (Triticum aestivum L.) grain hardness is controlled by the $\mathrm{Ha}$ locus, which is composed of two closely linked genes, Puroindoline a (Pina) and Puroindoline $b$ (Pinb). Hard grain results from mutations in either of the Pin genes. Previous results have shown that the Pina-D1b (Pina null) allele has harder grain than other naturally occurring Pin alleles. Our goal was to create, identify, and characterize a double null Pin genotype by identifying a Pinb null mutation in a variety carrying the Pina-D1l null allele. Seeds of Fortuna, which has a premature stop codon in Pina, were treated with ethyl methanesulfonate. Two premature stop codon mutations were identified in Pinb using direct sequencing. The double null Pin haplotype was characterized after backcrossing to the parent variety Fortuna to create Pina null populations segregating for the presence of Pinb. The double null group was 6 units harder than the single null with no difference in other kernel characteristics. The milling characteristics differed between the two classes; the double null class had less break flour with a greater fraction of large and a smaller fraction of small flour particles compared with the single null class. Neither water absorption nor loaf volume was impacted by the change in grain hardness; however, $\mathrm{Na}_{2} \mathrm{CO}_{3}$ tests indicated greater starch damage in the double nulls. The double null Pin genotype may find a niche in hard wheat products for which flours with larger particle size are desired.
Wheat (Triticum aestivum L.) is the basic ingredient for nearly all bread and pastry products. It is a major contributor to human nutrition as a source of carbohydrates, protein, and dietary fiber (reviewed in Shewry and Hey 2015). Wheat is separated into two distinct classes depending on whether it has soft or hard endosperm texture. Flour extracted from hard wheats is used to produce bread and other leavened products, whereas soft wheat flour is used to produce cookies, cakes, and pastries (Pomeranz and Williams 1990; Morris and Rose 1996).

The hardness $(\mathrm{Ha})$ locus, located on the short arm of chromosome 5D (Mattern et al. 1973; Law et al. 1978), controls much of the variation in wheat grain hardness (Campbell et al. 1999). This locus is made up of two closely linked genes, Puroindoline a (Pina) and Puroindoline $b$ (Pinb). Each gene produces a small (approximately 13,000) cysteine-rich basic protein (Dubreil et al.1998). When combined, these two proteins are referred to collectively as friabilin. Friabilin is a marker protein for grain hardness and is found on the surface of endosperm starch granules. Friabilin is in greater abundance on the starch surface of soft wheat than on hard wheat (Greenwell and Schofield 1986; Giroux and Morris 1998; Hogg et al. 2004). Wild-type alleles of both Pin genes give rise to soft grain texture, whereas mutations in either of the Pin genes are found in all hard wheat genotypes (Giroux and Morris 1997, 1998). There is no difference in the starch granules or the storage protein between hard and soft wheats (Barlow et al. 1973; Simmonds 1974). Therefore, endosperm texture difference must be a result of degree to which friabilin binds to starch granules. Hogg et al. (2004) and Wanjugi et al. (2007) showed soft grain is produced when both PINs bind cooperatively to starch granules.

Cultivated soft wheat varieties have the same wild-type Pina-Dla and Pinb-Dla alleles (Chen et al. 2006), but both Gedye et al. (2004) and Massa et al. (2004) identified novel Pina-D1/Pinb-D1 haplotypes in Aegilops tauschii, the donor of the D genome of bread wheat, which all conferred a soft grain texture. Four novel Ae. tauschii Pina-D1/Pinb-D1 haplotypes were introgressed into a

$\dagger$ Corresponding author. Phone: +1.406.994.5057. E-mail: jmmartin@montana.edu

Department of Plant Sciences and Plant Pathology, Montana State University, Bozeman, MT 59717, U.S.A.

https://doi.org/10.1094/CCHEM-04-17-0071-RW

(C) 2017 AACC International, Inc. soft wheat background, and grain hardness was increased from 3.8 to 12.6 hardness units (Reynolds et al. 2010).

Naturally occurring Pina and Pinb mutations resulting in hard grain texture have been observed in germplasm surveys (Morris et al. 2001; Chen et al. 2013). One of two haplotypes, PinaDla/Pinb-DIb and Pina-D1b/Pinb-Dla, are present in the vast majority of U.S. hard wheats (Morris et al. 2001). The Pinb-Dlb allele contains a glycine to serine substitution in PINB at the 46th amino acid (Giroux and Morris 1997, 1998), whereas Pina$D 1 b$ is a null mutation arising from a Pina gene deletion. Allelic variation within hard wheats results in grain hardness variation within the hard wheat market class, with the Pina null allele being harder than the other common Pin alleles. Ma et al. (2009) and Takata et al. (2010) using Pin near-isogenic lines and Martin et al. (2001) using a recombinant inbred line population showed that seeds containing the Pina-D1b/Pinb-Dla haplotype were 6-9 units harder than seeds containing the Pina-Dla/Pinb-D1b haplotype. Null mutations exist for Pinb, but Pinb null seeds are not as hard as the Pina-D1b null (Feiz et al. 2009b; Ma et al. 2009). Even though allelic variation at Pin loci exists within the hard wheat class, the total range in grain hardness is only about 10 units, with Pina-D $1 b$ ranking as the allele conferring the highest grain hardness (Takata et al. 2010). Feiz et al. (2009a, 2009b) identified mutations in both Pin loci that gave grain hardness outside the range of naturally occurring alleles within both the soft and hard classes after treating a soft wheat variety with ethyl methanesulfonate (EMS).

Even small differences in grain hardness within the hard wheat class cited above can lead to differences in end-use properties. Martin et al. (2001) showed seeds containing the Pina-Dla/Pinb-D1b haplotype gave more flour and break flour yield with lower ash and greater loaf volume compared with those containing the harder Pina-D1b/Pinb-Dla haplotype. Ma et al. (2009) found similar increased flour yield for these haplotypes. Kammeraad et al. (2016) compared milling behavior of Pin near-isogenic lines having grain hardness ranging from approximately 50 to 73 units and found flour yield was not related to grain hardness, whereas break flour yield was inversely proportional to grain hardness level. Flour particle size distribution was also altered, because softer genotypes had a greater proportion of smaller particles and a smaller proportion of larger particles.

Early reports identified the nonfunctional Pina null (Pina-D1b allele) mutation by the absence of a mutation in Pinb, a hard grain phenotype, failure to produce a Pina amplicon via polymerase chain 
reaction (PCR), and the absence of PINA from a Triton X-114 protein extraction (Giroux and Morris 1997). Morris and Bhave (2008) reported the Pina-D1b null has a 15,300 bp deletion. An additional Pina null mutation resulting from a stop codon in Pina has been described (Gazza et al. 2005) and designated Pina-D1l (Morris and Bhave 2008). Obtaining a Pin haplotype consisting of Pina and Pinb null mutations via recombination is unlikely because the two Pin genes are only separated by about $20 \mathrm{~kb}$ (Chantret et al. 2005). A deletion-derived double null Pin genotype was reported (Tranquilli et al. 2002; Ikeda et al. 2005) and designated by Morris and Bhave (2008) as Pina-Dlk.

A haplotype in which both Pin genes are nonfunctional may have harder grain than the single Pina null. Takata et al. (2010) used near-isogenic lines to compare the Pina-DIb/Pinb-Dla haplotype with the Pina-Dlk double null. The Pina-Dlk double null was numerically, although not statistically, harder than Pina-D1b/Pinb-Dla.

Our goal was to create, identify, and characterize a double null Pin genotype by identifying a null mutation in Pinb in the variety Fortuna, which carries the Pina-D1l null mutation. The double null Pin haplotype was characterized after backcrossing to the parent variety Fortuna to create Pina null populations segregating for the presence of Pinb. The impact of these allelic variants was assessed on kernel, flour, milling, and bread baking traits.

\section{MATERIALS AND METHODS}

Approximately 5,000 $\mathrm{M}_{0}$ seeds of the hard red spring wheat cultivar Fortuna (CI 13596) (Lebsock et al. 1967) were treated with $1 \%$ EMS using methods first described by Slade et al. (2005) and modified by Feiz et al. (2009a, 2009b), and surviving plants were advanced in the greenhouse. Fortuna is a single null genotype with the Pin haplotype Pina-D1l /Pinb-Dla. The $\mathrm{M}_{1}$ population was advanced in the greenhouse, and $350 \mathrm{M}_{1}$-derived lines were planted in single rows in the field at the Post Agronomy Farm near Bozeman, Montana, in 2015. Leaf tissue for DNA preparations was collected and pooled at the two- to three-leaf stage from four plants per row. Lines were screened for mutations in Pinb via PCR and direct sequencing using the primers PB5 (Gautier et al. 1994) and Cat 3.4 (Swan et al. 2006). The PCR master mix for one sample contained $14.13 \mu \mathrm{L}$ of $\mathrm{H}_{2} \mathrm{O}, 5 \mu \mathrm{L}$ of GoTaq $5 \mathrm{X}$ buffer (Promega, Madison, WI, U.S.A.), $2 \mu \mathrm{L}$ of $25 \mathrm{mM} \mathrm{MgCl}_{2}, 2 \mu \mathrm{L}$ of $2 \mu \mathrm{M}$ each of deoxynucleotide triphosphate, $0.52 \mu \mathrm{L}$ of PB5, $0.52 \mu \mathrm{L}$ of Cat 3.4, and $0.13 \mu \mathrm{L}$ of GoTaq polymerase (Promega). The PCR program consisted of a four min initial denaturation at $96^{\circ} \mathrm{C}$, followed by 35 cycles of $96^{\circ} \mathrm{C}$ for $30 \mathrm{~s}, 55^{\circ} \mathrm{C}$ for $30 \mathrm{~s}, 72^{\circ} \mathrm{C}$ for $1 \mathrm{~min}$, and a final extension of $72^{\circ} \mathrm{C}$ for $7 \mathrm{~min}$. Amplicons were sequenced using the primer Cat 3.4, and resultant sequences were screened for mutations using the Seqman Pro 12 program (DNAStar, Madison, WI, U.S.A.).

The two selected Pin mutation-containing lines were crossed to the nonmutated Fortuna parent to create segregating populations. Both segregating $\mathrm{F}_{2}$ populations were screened using methods described above to identify single null (Pina-D1l/Pinb-Dla) and double null (Pina-D1l/Pinb-D1Q20 or Pina-D1//Pinb-D1W116) homozygotes. Seed was harvested from single homozygous $F_{2}$ plants. Seeds from 10 single null (Pina-D1//Pinb-Dla) and 10 double null (PinaD1l/Pinb-D1Q20Stop or Pinb-D1W116Stop) homozygous $\mathrm{F}_{2}$ plants from each population were planted as a single row in a winter nursery in Arizona for seed increase.

Seeds $\left(\mathrm{F}_{2: 4}\right)$ from 10 single null and 10 double null lines from each of the two Pinb mutant cross populations plus the Fortuna parent were planted in a randomized block design with two replications at the Post Agronomy Farm near Bozeman, Montana, in 2016. Each plot consisted of two $3 \mathrm{~m}$ rows spaced $30 \mathrm{~cm}$ apart. Each plot was harvested with a plot combine at maturity. Grain samples were cleaned and weighed. Grain protein was measured using near- infrared reflectance (NIR) with the Infratec 1241 grain analyzer (Foss North America, Eden Prairie, MN, U.S.A.). Grain hardness, kernel weight, and kernel diameter were measured on 100 kernel samples with the single-kernel characterization system (SKCS) (Perten Instruments, Springfield, IL, U.S.A.). Five single and five double null lines from each population were selected for a milling study. Wheat grain was tempered to $14.5 \%$ moisture (fresh weight basis). Grain samples were milled with a Brabender Quadrumat Senior mill (C. W. Brabender, South Hackensack, NJ, U.S.A.) (AACC International Approved Method 26-21.02). Bran, shorts, break flour, and reduction flour were collected separately. Total flour yield was determined as the break plus reduction flour divided by total recovered product. Flour was size separated with 149, 75, and $53 \mu \mathrm{m}$ U.S. standard sifting screens (Seedburo Equipment, Chicago, IL, U.S.A.) on a rotating sifter (Ro-Tap RX-29, Leval Lab, Quebec, Canada), and the sieve products were weighed. These data were used to determine flour particle size distribution. Flour protein was determined with an Infratec 1241 grain analyzer with a flour NIR attachment (Foss North America) and expressed at a $14.0 \%$ moisture basis proportional to the reference method, which utilizes a LECO FP-528 (LECO, Saint Joseph, MI, U.S.A.) nitrogen analyzer (AACCI Approved Method 46-30.01). Flour ash was predicted by a near-infrared method (AACCI Approved Method 08-21.01). The solvent retention capacity (SRC) test using sodium carbonate $\left(\mathrm{Na}_{2} \mathrm{CO}_{3}\right)$ as the solvent was performed on all flour samples following AACCI Approved Method 56-11.01 with the modifications described by Bettge et al. (2002).

Mixograph dough properties were evaluated following AACCI Approved Method 54-40.02. Tolerance to mixing was scored on a 0-9 scale by visually comparing mixographs to standard reference mixograph charts, adjusted for protein content (Pomeranz 1987). Standard bake tests were conducted following AACCI Approved Method 10-10.03. Bake absorption was determined as the amount of water required to bring dough to proper consistency for bread baking. Bake mixing time was recorded as time to bring dough to optimum properties for baking. Loaf volume was determined by the volume of canola seeds displaced. Crumb grain was scored on a visual 1 (excellent) to 9 (unsatisfactory) scale by an experienced baker.

Each response variable was analyzed via analysis of variance using PROC MIXED in SAS version 9.3 software (SAS Institute Cary, NC, U.S.A.). The model included block, population, Pin genotype (single or double null) population $\times$ Pin genotype, and $\mathrm{F}_{2: 4}$ line within population $\times$ Pin genotype combination. The $\mathrm{F}_{2: 4}$ line within population $\times$ Pin genotype combination was considered random, and all other factors were considered fixed effects. Pin genotype means for each population and averages over populations were compared using a $t$ statistic. Linear correlations among selected traits were computed by using the $\mathrm{F}_{2: 4}$ line means averaged over replications.

\section{RESULTS}

Two premature stop codon mutations were identified, $Q 20^{*}$ (CAA to TAA) and W116* (TGG to TGA), following direct sequencing of Pinb from this EMS population. Each mutant was then crossed to the Fortuna parent to create segregating populations.

The double nulls (Pina-D1l/Pinb-D1 Q20* and Pina-D1l/Pinb-D1 W116*) were about 6 units harder than the single null (Pina-D1l/ Pinb-Dla) genotype (Table I). The single and double null genotypes did not differ for kernel weight, kernel diameter, or grain protein. Grain yield did not differ between single and double null classes, but grain yield for the parent variety Fortuna was higher than that for the segregating populations. This is indicative of background mutations following EMS treatment.

Total flour yield did not differ, but the double null genotype had $2.2 \%$ less break flour $(P<0.01)$ than the single null genotype when averaged over the two populations (Table II). The double 
null genotype tended to have less bran $(P=0.03)$ and more shorts $(P=0.04)$ when averaged over both populations. Flour ash was slightly higher for the double null than for the single null genotype $(P=0.01)$ averaged over populations. SRC using $\mathrm{Na}_{2} \mathrm{CO}_{3}$ is a proxy for starch damage, and on that basis the double null genotype suffered more starch damage than did the single null group $(P<0.01)$.

The two genotypes displayed different flour particle size distribution patterns (Table III). The double null genotype had a higher proportion in the $>149$ and $>75$ to $<149 \mu \mathrm{m}$ fractions and a lower proportion in the $<53 \mu \mathrm{m}$ fraction compared with the single null genotype when averaged over the two populations. No differences were detected for the $>53$ to $<75 \mu \mathrm{m}$ fraction. The differences between genotypes tended to be greater for the Fortuna/Pina-D1l/ Pinb-D1 W116* population, but the population $\times$ genotype interaction was not significant $(P<0.12)$ for any of the fractions.

The Fortuna/Pina-D1l/Pinb-D1 W116* population did not show any difference between classes for any of the dough or bread characteristics (Table IV). But the Fortuna/Pina-D1l/Pinb-D1 Q20* had a shorter mixograph mix time and bake mix time (data not shown) and less tolerance to mixing compared with the Pina-DIl/ Pinb-Dla group. This gave significant population $\times$ genotype interactions for mixograph tolerance $(P<0.05)$, mixograph mixing time $(P<0.01)$, and bake mixing time $(P<0.05)$.

We examined the linear relation between grain hardness and milling-related traits. Grain hardness differences explained $74 \%$ of the variation in break flour yield (Fig. 1). In contrast, grain hardness was not related to flour yield ( $r=0.02, P=0.93)$. Grain hardness was also highly correlated with $\mathrm{Na}_{2} \mathrm{CO}_{3} \operatorname{SRC}(r=0.86, P<0.01)$. Grain hardness correlated with the percent retained for the various particle size fractions (Table V). It was positively related to percent retained for $>149$ and $>75$ to $<149 \mu \mathrm{m}$ fractions, negatively related to the percent retained at $<53 \mu \mathrm{m}$, but not related to percent retained for the $>53$ to $<75 \mu \mathrm{m}$ fraction.

\section{DISCUSSION}

Our goal was to create, identify, and characterize null alleles for both Pina and Pinb in a single genotype. We accomplished that by identifying two independent null mutations in Pinb in the variety Fortuna, which has a null mutation in Pina resulting from a premature stop codon (Pina-D1l). The two double null mutant genotypes were then crossed to the Fortuna parent to create segregating populations, which were evaluated for kernel, milling, and baking characteristics. A genotype with harder grain than currently available $P$ in genotypes could expand the phenotypic variation available for grain hardness and related milling traits. Sequencing of Pinb-D1 from approximately 350 EMS Fortuna $\mathrm{M}_{1}$ lines detected two nonsense mutations, Pinb-D1Q20* and Pinb-D1W116*. Feiz et al. (2009b) found a $1 / 11 \mathrm{~kb}$ mutation discovery rate in Pinb-Dla after EMS treatment in the soft white spring wheat Alpowa. They found $11 \%$ of their mutations were nonsense mutations. Our goal was to

TABLE I

Mean Values for Kernel Characteristics of Single Null (Pina-D1l/Pinb-D1a) and Double Null (Pina-D1l/Pinb-D1Q20* and Pina-D11/Pinb-D1W116*) Puroindoline $\mathrm{F}_{2}$-Derived Lines Obtained from Crossing Fortuna (Pina-D1l/Pinb-D1a) with Two Fortuna EMS-Derived Double Null Lines (Pinb-D1Q20* and Pinb-D1W116*)a

\begin{tabular}{|c|c|c|c|c|c|c|}
\hline Puroindoline Genotype & $\begin{array}{l}\text { Number } \\
\text { of Lines }\end{array}$ & Grain Yield (g/ha) & Grain Hardness & Kernel Weight (mg) & Kernel Diameter (mm) & $\begin{array}{c}\text { Grain } \\
\text { Protein }(\mathrm{g} / \mathrm{kg})\end{array}$ \\
\hline $\begin{array}{l}\text { Fortuna Pina-D1l/Pinb-D1a } \\
\text { Fortuna/Pinb-Dl O20* }\end{array}$ & & $5,257 \pm 63$ & $63.2 \pm 0.6$ & $36.3 \pm 0.8$ & $2.74 \pm 0.01$ & $151 \pm 0.0$ \\
\hline Pina-D1l/Pinb-D1Q20* & 5 & $3,693 \pm 124$ & $72.8 \pm 0.8$ & $35.7 \pm 0.5$ & $2.79 \pm 0.01$ & $159 \pm 0.9$ \\
\hline$P$ value & & 0.13 & $<0.01$ & 0.77 & 0.51 & 0.10 \\
\hline \multicolumn{7}{|l|}{ Fortuna/Pinb-D1 W116* } \\
\hline Pina-D1l/Pinb-D1a & 5 & $4,079 \pm 48$ & $67.0 \pm 1.3$ & $36.3 \pm 0.7$ & $2.77 \pm 0.02$ & $154 \pm 1.4$ \\
\hline \multicolumn{7}{|l|}{ Average } \\
\hline Pina-D1l/Pinb-D1a & 10 & $4,006 \pm 63$ & $67.2 \pm 0.8$ & $36.1 \pm 0.5$ & $2.79 \pm 0.02$ & $155 \pm 0.9$ \\
\hline Pina-D1l/Pinb-D1stop & 10 & $3,918 \pm 163$ & $73.3 \pm 0.6$ & $36.1 \pm 0.3$ & $2.80 \pm 0.01$ & $157 \pm 0.8$ \\
\hline$P$ value & & 0.55 & $<0.01$ & 0.96 & 0.41 & 0.08 \\
\hline
\end{tabular}

a Hardness, individual kernel weight, and kernel diameter mean were determined by the single-kernel characterization system. Grain protein was determined by NIR and is reported on a $12 \%$ moisture basis. EMS = ethyl methanesulfonate.

TABLE II

Mean Values for Flour Milling Characteristics of Single Null (Pina-D1l/Pinb-D1a) and Double Null (Pina-D1l/Pinb-D1Q20* and Pina-D1l/Pinb-D1W116*) Puroindoline F $_{2}$-Derived Lines Obtained from Crossing Fortuna (Pina-D11/Pinb-D1a) with Two Fortuna EMS-Derived Double Null Lines (Pinb-D1Q20* and Pinb-D1W116*)

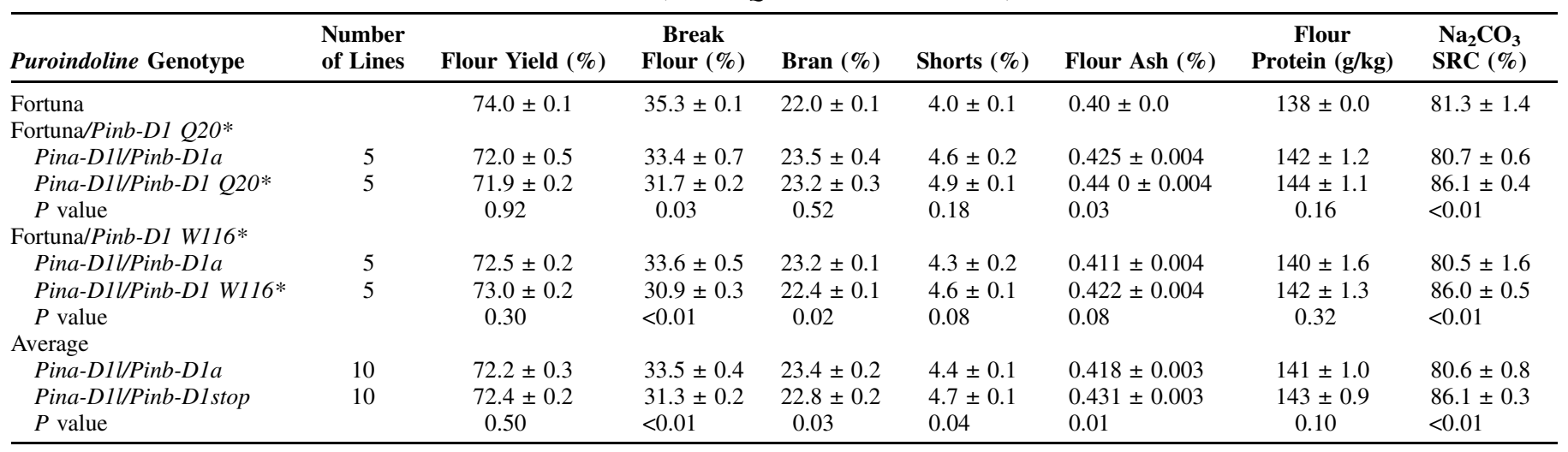

${ }^{a}$ Flour protein and solvent retention capacity (SRC) reported on a $14 \%$ moisture basis. EMS = ethyl methanesulfonate. 
identify nonsense mutations rather than all mutations in Pinb, so a mutation rate was not determined. We sequenced about $157.5 \mathrm{~kb}$ (approximately $350 \mathrm{M}_{1}$ lines $\times 0.45 \mathrm{~kb}$ ); from this $\mathrm{M}_{1}$ population, based on the results of Feiz et al. (2009b), we would have expected one or two nonsense mutations. Both Tranquilli et al. (2002) and Ikeda et al. (2005) reported double null Pin genotypes (designated Pina-D $1 k$ ) that resulted from deletions of both Pina and Pinb. But the number of adjacent linked genes also deleted on 5DS is unknown. The double null genotypes we have created are unique compared with other reports of double null Pin genotypes in that closely linked genes have not been deleted.

Grain hardness differences within the hard wheat class can manifest themselves in differential milling characteristics, including the yield and flour particle size distribution (Ma et al. 2009; Kammeraad et al. 2016). Our double null Pin genotype class was about 6 units harder than the single null genotype class, but other kernel-related traits did not differ between classes (Table I). In addition, the harder double null class had less break flour with a greater proportion of large flour particles $(>149$ and $>75$ to $<149 \mu \mathrm{m}$ fractions) but a smaller proportion of small flour particles, $(<53 \mu \mathrm{m}$ fraction) than the single null class (Table III). Despite the redistribution of flour particle sizes, total flour yield did not differ between classes. Tranquilli et al. (2002), using chromosome substitution lines in Chinese Spring, found the 5D substitution line with both Pina and Pinb deleted had harder grain than the 5D substitution line with only Pina deleted. Takata et al. (2010) created isogenic lines for the single null Pina-D1b/Pinb-Dla and double null (Pina-Dlk) as well as for other Pin haplotypes. The double null Pina-D $l k$ was not statistically different from the single null (PinaDlb/Pinb-D1a) in grain hardness or flour yield, but they did find average flour particle size was larger for the Pina-Dlk lines than for Pina-D1b/Pinb-Dla lines $(P<0.05)$. These comparisons may have been confounded by deletion of other closely linked genes.

Hard wheats have greater total flour yield but less break flour yield than do soft wheats across a wide range of grain hardness (Hogg et al. 2005; Martin et al. 2007). Our results showed a highly significant $(P<0.01)$ negative association between grain hardness and break flour yield (Fig. 1), but grain hardness was not related to total flour yield. Kammeraad et al. (2016) found similar results, in which grain hardness was negatively related to break flour yield but not related to total flour yield for 10 Pin alleles within the hard wheat class.

Starch granules are dislodged from the protein matrix during milling. For soft wheats, fractures tend to occur around rather than through starch granules, yielding a high proportion of intact starch granules. In hard wheats starch granules adhere more tightly to the protein matrix, requiring more energy to extract, and fractures tend to occur through starch granules, giving a higher proportion of fractured or damaged starch granules. $\mathrm{SRC}$ with $\mathrm{Na}_{2} \mathrm{CO}_{3}$ solvent has been used to estimate starch damage primarily in soft wheats. Studies have shown the $\mathrm{Na}_{2} \mathrm{CO}_{3}$ SRC test was highly correlated with starch damage across flours from soft and hard wheat (Duyvejonck et al. 2011) $(r=0.91, P<0.05)$, within hard red spring wheat (Hammed et al. 2015) $(r=0.67, P<0.05)$, and among hard

TABLE III

Mean Values for Flour Particle Size Distribution Fractions of Single Null (Pina-D1l/Pinb-D1a) and Double Null (Pina-D1l/Pinb-D1Q20* and Pina-D1l/Pinb-D1W116*) Puroindoline F $_{2}$-Derived Lines Obtained from Crossing Fortuna (Pina-D1l/Pinb-D1a) with Two Fortuna EMS-Derived Double Null Lines (Pinb-D1Q20* and Pinb-D1W116*) ${ }^{\text {a }}$

\begin{tabular}{|c|c|c|c|c|c|}
\hline Puroindoline Genotype & Number of Lines & $>149 \mu \mathrm{m}(\%)$ & $>75$ to $<149 \mu \mathrm{m}(\%)$ & $>53$ to $<75 \mu \mathrm{m}(\%)$ & $<53 \mu \mathrm{m}(\%)$ \\
\hline Fortuna & & $4.2 \pm 0.0$ & $65.6 \pm 0.7$ & $17.7 \pm 0.9$ & $12.5 \pm 0.1$ \\
\hline \multicolumn{6}{|l|}{ Fortuna/Pinb-D1Q20* } \\
\hline Pina-D1l/Pinb-D1a & 5 & $5.3 \pm 0.5$ & $66.2 \pm 0.3$ & $16.1 \pm 1.6$ & $12.4 \pm 1.6$ \\
\hline Pina-D1l/Pinb-D1Q20* & 5 & $6.4 \pm 0.4$ & $66.9 \pm 0.3$ & $17.3 \pm 0.9$ & $9.4 \pm 0.9$ \\
\hline$P$ value & & 0.10 & 0.15 & 0.46 & 0.08 \\
\hline \multicolumn{6}{|l|}{ Fortuna/Pinb-D1W116* } \\
\hline Pina-D1l/Pinb-Dla & 5 & $4.6 \pm 0.5$ & $66.4 \pm 0.3$ & $17.1 \pm 1.3$ & $11.9 \pm 1.3$ \\
\hline Pina-D1l/Pinb-D1W116* & 5 & $6.7 \pm 0.3$ & $68.1 \pm 0.4$ & $16.1 \pm 0.7$ & $9.1 \pm 0.7$ \\
\hline$P$ value & & $<0.01$ & $<0.01$ & 0.53 & 0.11 \\
\hline \multicolumn{6}{|l|}{ Average } \\
\hline Pina-D1l/Pinb-D1a & 10 & $5.0 \pm 0.4$ & $66.3 \pm 0.2$ & $16.6 \pm 1.0$ & $12.1 \pm 1.0$ \\
\hline Pina-D1l/Pinb-D1stop & 10 & $6.5 \pm 0.2$ & $67.5 \pm 0.3$ & $16.7 \pm 0.6$ & $9.2 \pm 0.5$ \\
\hline$P$ value & & $<0.01$ & $<0.01$ & 0.93 & 0.02 \\
\hline
\end{tabular}

a EMS = ethyl methanesulfonate.

TABLE IV

Mean Values for Dough Mixing and Bread Characteristics of Single Null (Pina-D1l/Pinb-D1a) and Double Null (Pina-D1l/Pinb-D1Q20* and Pina-D1l/Pinb-D1W116*) Puroindoline F $_{2}$-Derived Lines Obtained from Crossing Fortuna (Pina-D1l/Pinb-D1a) with Two Fortuna EMS-Derived Double Null Lines (Pinb-D1Q20* and Pinb-D1W116*)

\begin{tabular}{|c|c|c|c|c|c|c|}
\hline Puroindoline Genotype & Number of Lines & $\begin{array}{c}\text { Mixing } \\
\text { Tolerance }\end{array}$ & $\begin{array}{c}\text { Mixograph } \\
\text { Mixing Time (min) }\end{array}$ & $\begin{array}{l}\text { Mixograph Water } \\
\text { Absorption }(\%)\end{array}$ & Loaf Volume $\left(\mathrm{cm}^{3}\right)$ & $\begin{array}{c}\text { Crumb } \\
\text { Grain Score }\end{array}$ \\
\hline Fortuna & & $3.0 \pm 1.0$ & $2.5 \pm 0.0$ & $63.5 \pm 0.8$ & $1,160 \pm 5$ & $6.5 \pm 0.5$ \\
\hline \multicolumn{7}{|l|}{ Fortuna/Pinb-D1Q20* } \\
\hline Pina-D1l/Pinb-D1a & 5 & $1.6 \pm 0.3$ & $2.19 \pm 0.15$ & $64.6 \pm 0.3$ & $1,132 \pm 13$ & $5.7 \pm 0.3$ \\
\hline Pina-D1l/Pinb-D1Q20* & 5 & $1.0 \pm 0.0$ & $1.85 \pm 0.13$ & $64.9 \pm 0.5$ & $1,100 \pm 16$ & $6.2 \pm 0.3$ \\
\hline$P$ value & & 0.04 & 0.02 & 0.69 & 0.10 & 0.12 \\
\hline \multicolumn{7}{|l|}{ Fortuna/Pinb-D1W116* } \\
\hline Pina-D1l/Pinb-D1a & 5 & $3.0 \pm 0.3$ & $2.41 \pm 0.15$ & $65.2 \pm 0.4$ & $1,133 \pm 12$ & $5.9 \pm 0.2$ \\
\hline Pina-D1l/Pinb-D1W116* & 5 & $3.2 \pm 0.1$ & $2.66 \pm 0.13$ & $65.9 \pm 0.5$ & $1,147 \pm 11$ & $6.0 \pm 0.2$ \\
\hline$P$ value & & 0.47 & 0.08 & 0.32 & 0.44 & 0.76 \\
\hline \multicolumn{7}{|l|}{ Average } \\
\hline Pina-D1l/Pinb-D1a & 10 & $2.3 \pm 0.4$ & $2.3 \pm 0.1$ & $64.9 \pm 0.4$ & $1,132 \pm 11$ & $5.8 \pm 0.2$ \\
\hline Pina-D1l/Pinb-D1stop & 10 & $2.1 \pm 0.5$ & $2.3 \pm 0.2$ & $65.4 \pm 0.5$ & $1,123 \pm 17$ & $6.1 \pm 0.2$ \\
\hline$P$ value & & 0.32 & 0.64 & 0.33 & 0.50 & 0.19 \\
\hline
\end{tabular}

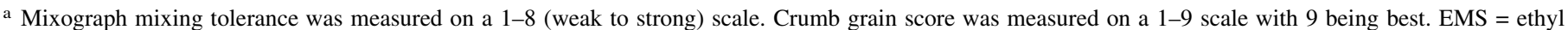
methanesulfonate. 
Pin near-isogenic lines (Takata et al. 2010) $(r=0.98, P<0.05)$. We used the $\mathrm{Na}_{2} \mathrm{CO}_{3} \mathrm{SRC}$ test as a proxy for starch damage, and the harder double null class absorbed more solvent than the softer single null class (Table II), implying greater starch damage for the double null group. Takata et al. (2010) observed that the double null Pina$D l k$ near-isogenic lines suffered significantly more starch damage than the single null Pina-D1b/Pinb-Dla near-isogenic lines even though the two differed by only three units on the SKCS hardness scale.

Hard wheat flours absorb more water than do soft wheat flours over a range of grain hardness levels (Hogg et al. 2005; Martin et al. 2007), largely because damaged starch absorbs more water than intact starch. We did not detect a difference in mixograph water absorption between the single null and double null classes (Table IV). Martin et al. (2001) also did not find a difference for mixograph water absorption between Pina-D1b/Pinb-Dla and Pina/Dla/Pinb-D1b allelic classes in a recombinant inbred population, in which the two classes differed by only 6 hardness units. A 6 unit hardness difference and apparent starch damage difference were not sufficient to effect a detectable change in water absorption.

Loaf volume is the most important measure of bread quality. The impact of $P$ in allelic variation on loaf volume from previous studies has been inconsistent. Martin et al. (2001) found the softer Pinb$D 1 b$ had higher loaf volume than the harder Pina-DIb allele in two independent recombinant inbred populations of spring wheat, in which the two haplotypes differed by approximately 6 hardness

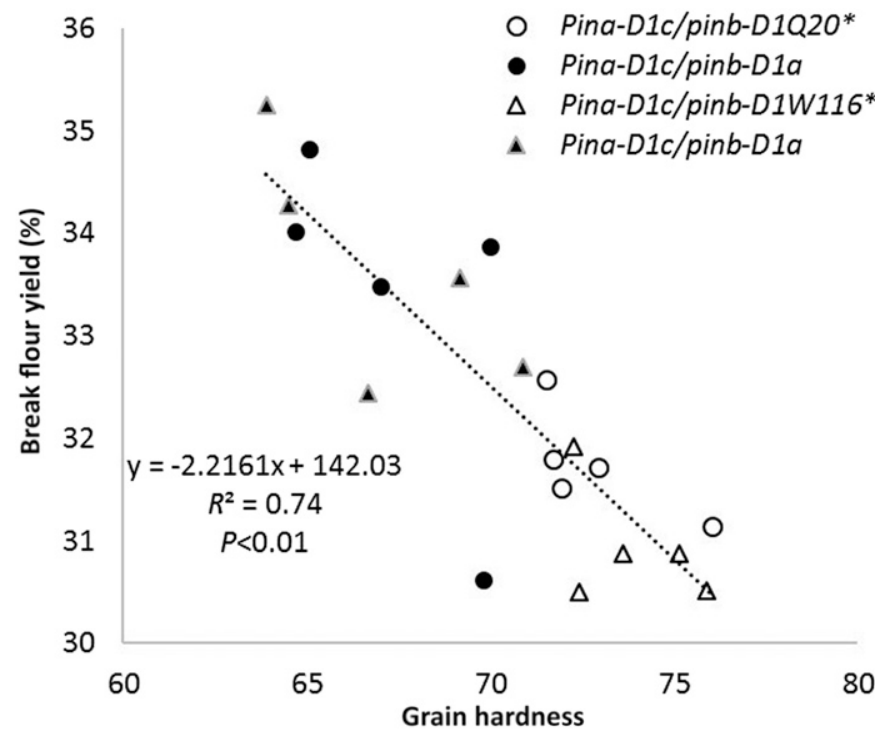

Fig. 1. Relationship between grain hardness and break flour yield for single null (Pina-D1l/Pinb-D1b) and double null (Pina-D1//Pinb-D1Q20* and Pina-D1//Pinb-D1W116*) Puroindoline $\mathrm{F}_{2}$-derived lines obtained from crossing Fortuna (Pina-D1//Pinb-D1a) with two Fortuna EMS-derived double null lines (Pinb-D1Q20* and Pinb-D1W116*). units. In contrast, Kammeraad et al. (2016) found no difference in loaf volume when near-isogenic lines with $P$ in alleles conferring hard grain were compared with their soft wild-type counterparts. In the present study we found no difference between single and double null classes for loaf volume. Hard wheats generally suffer more starch damage during milling, and their flours absorb more water than soft wheats. The approximately 6 unit hardness difference in our populations did result in a difference in starch damage as measured by the SRC test using $\mathrm{Na}_{2} \mathrm{CO}_{3}$. But we did not detect any change in water absorption. That may not be surprising, because Martin et al. (2001) did not observe a difference in water absorption in their recombinant inbred population in which the Pin haplotypes differed by approximately 6 units.

The two independent Pinb mutations created through EMS mutagenesis were crossed to Fortuna to create two segregating populations. These two populations showed similar results across all traits except for the dough mixing traits, for which the results varied depending on the population (Table IV). In particular, the double null class had lower mixing tolerance and time than the single null class for the Pina-D1//Pinb-D1Q20* population, but no reduction was observed for the Pina-D1l/Pinb-D1W116* population. It is noteworthy that both allelic classes for the Pina-D1l/Pinb-D1Q20* population were well below the Fortuna parent for dough mixing tolerance and time (Table IV), whereas the two classes were more similar to the Fortuna parent for the Pina-D1//Pinb-D1W116* population. The difference in response for dough mixing traits occurred even though flour protein did not differ. One explanation is that the Pina-D1l/Pinb-D1W116* parent had multiple mutations affecting dough characteristics.

\section{CONCLUSIONS}

We created and characterized two genotypes that have null mutations in both Pina and Pinb (double null) and then created populations segregating for the single Pina null (Pina-D1//Pinb-Dla) and double null genotypes. The double null group was 6 units harder than the single null with no difference in other kernel characteristics. The milling characteristics differed between the two classes, in which the double null class had less break flour with a greater fraction of large flour particles and a smaller fraction of small flour particles compared with the single null class. Neither water absorption nor loaf volume was impacted by the change in grain hardness; however, $\mathrm{Na}_{2} \mathrm{CO}_{3}$ tests indicated greater starch damage in the double nulls. Results were consistent across the two populations, except mixing time and tolerance differed between classes for one population but not the other, probably because of an abundance of mutations in other genes in the double null parent. The double null Pin genotype may find a niche in hard wheat products for which flours with larger particle size, maximum starch damage, and higher water absorption are desired. The double null Pin genotype may have milling properties similar to durum wheat (Triticum durum subsp. durum) because both lack functional $P$ in genes, and it could have application for pasta manufacture. The harder double null Pin genotype may require more energy to mill, but that may be offset by less energy required during flour sifting than softer Pin haplotypes.

TABLE V

Correlations $(r)$ Between Grain Hardness, Flour Particle Size Fractions, and Milling Yields ${ }^{\mathbf{a}}$

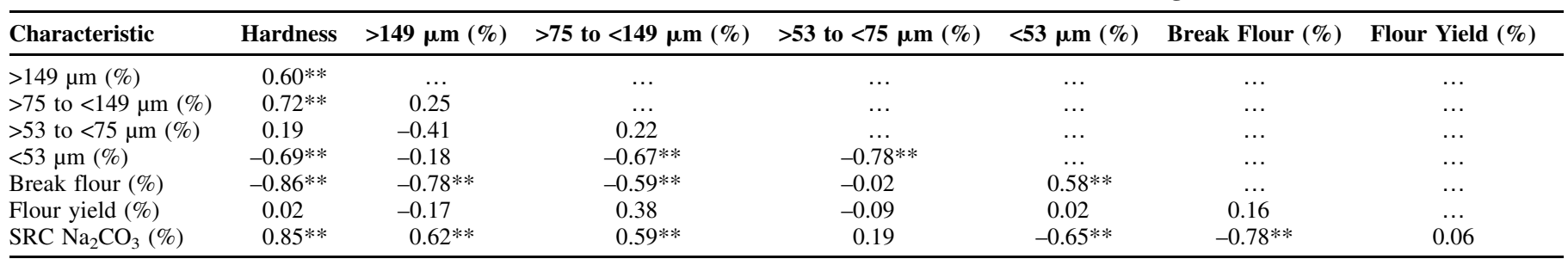

a $n=20$; ** indicates significantly different from 0.0 with $P<0.01$. SRC $=$ solvent retention capacity. 


\section{LITERATURE CITED}

AACC International. Method 08-21.01. Prediction of ash content in wheat flour-Near-infrared method. Approved November 8, 2000. Method 10-10.03. Optimized straight-dough bread-making method. Approved November 8, 1995. Method 26-21.02. Experimental milling-Bühler method for hard wheat. Approved October 12, 1988. Method 46-30.01. Crude protein-Combustion method. Approved November 8, 1995. Method 54-40.02. Mixograph method. Approved November 8, 1995. Method 56-11.01. Solvent retention capacity profile. Proposed November 3, 1999. [Archived method.] Available online only. AACCI: St. Paul, MN.

Barlow, K. K., Buttrose, M. S., Simmonds, D. H., and Vesk, M. 1973. The nature of the starch protein interface in wheat endosperm. Cereal Chem. 50:443-454.

Bettge, A. D., Morris, C. F., DeMacon, V. L., and Kidwell, K. K. 2002. Adaptation of AACC Method 56-11, Solvent Retention Capacity, for use as an early generation selection tool for cultivar development. Cereal Chem. 79:670-674.

Campbell, K. G., Bergman, C. J., Gaulberto, D. G., Anderson, J. A., Giroux, M. J., Hareland, G., Fulcher, R. G., Sorrells, M. E., and Finney, P. L. 1999. Quantitative trait loci associated with kernel traits in a soft $\times$ hard wheat cross. Crop Sci. 39:1184-1195.

Chantret, N., Salse, J., Sabot, F., Rahman, S., Bellec, A., Laubin, B., Dubois, I., Dossat, C., Sourdille, P., Joudrier, P., Gautier, M., Cattolico, L., Beckert, M., Aubourg, S., Weissenbach, J., Caboche, M., Bernard, M., Leroy, P., and Chalhoub, B. 2005. Molecular basis of evolutionary events that shaped the hardness locus in diploid and polyploidy wheat species (Triticum and Aegilops). Plant Cell 17:1033-1045.

Chen, F., He, Z., Xia, X., Xia, L., Zhang, X., Lillemo, M., and Morris, C. F. 2006. Molecular and biochemical characterization of puroindoline $\mathrm{a}$ and $\mathrm{b}$ alleles in Chinese landraces and historical cultivars. Theor. Appl. Genet. 112:400-409.

Chen, F., Li, H., and Cui, D. 2013. Discovery, distribution and diversity of Puroindoline-D1 genes in bread wheat from five countries (Triticum aestivum L.). BMC Plant Biol. 13:125.

Dubreil, L., Gaborit, T., Bouchet, B., Gallant, D., Broekaert, W., Quillien, L., and Marion, D. 1998. Spatial and temporal distribution of the major isoforms of puroindolines (puroindoline-a and puroindoline-b) and non-specific lipid transfer protein (ns-LTPle(1)) of Triticum aestivum seeds: Relationships with their in vitro antifungal properties. Plant Sci. 138:121-135.

Duyvejonck, A. E., Lagrain, B., Pareyt, B., Courtin, C. M., and Delcour, J. A. 2011. Relative contribution of wheat flour constituents to solvent retention capacity profiles of European wheats. J. Cereal Sci. 53:312-318.

Feiz, L., Beecher, B., Martin, J., and Giroux, M. 2009a. In planta mutagenesis determines the functional regions of the wheat puroindoline proteins. Genetics 183:853-860.

Feiz, L., Martin, J., and Giroux, M. 2009b. Creation and functional analysis of new Puroindoline alleles in Triticum aestivum. Theor. Appl. Genet. 118:247-257.

Gautier, M. F., Aleman, M. E., Guirao, A., Marioen, D., and Joudier, P. 1994. Triticum aestivum puroindolines, two basic cystine-rich seed proteins: cDNA analysis and developmental gene expression. Plant Mol. Biol. 25:43-57.

Gazza, L., Nocente, F., Ng, P. K., and Pogna, N. E. 2005. Genetic and biochemical analysis of common wheat cultivars lacking puroindoline a. Theor. Appl. Genet. 110:470-478.

Gedye, K., Morris, C., and Bettge, A. 2004. Determination and evaluation of the sequence and textural effects of the puroindoline a and puroindoline $b$ genes in a population of synthetic hexaploid wheat. Theor. Appl. Genet. 109:1597-1603.

Giroux, M., and Morris, C. 1997. A glycine to serine change in puroindoline $\mathrm{b}$ is associated with wheat grain hardness and low levels of starch-surface friabilin. Theor. Appl. Genet. 95:857-864.

Giroux, M., and Morris, C. 1998. Wheat grain hardness results from highly conserved mutations in the friabilin components puroindoline a and b. Proc. Natl. Acad. Sci. U.S.A. 95:6262-6266.

Greenwell, P., and Schofield, J. 1986. A starch granule protein associated with endosperm softness in wheat. Cereal Chem. 63:379-380.

Hammed, A. M., Ozsisli, B., Ohm, J.-B., and Simsek, S. 2015. Relationship between solvent retention capacity and protein molecular weight distribution, quality characteristics, and breadmaking functionality of hard red spring wheat flour. Cereal Chem. 92:466-474.
Hogg, A., Beecher, B., Martin, J., Meyer, F., Talbert, L., Lanning, S., and Giroux, M. 2005. Hard wheat milling and bread baking traits affected by the seed-specific overexpression of puroindolines. Crop Sci. 45:871-878.

Hogg, A., Sripo, T., Beecher, B., Martin, J., and Giroux, M. 2004. Wheat puroindolines interact to form friabilin and control wheat grain hardness. Theor. Appl. Genet. 108:1089-1097.

Ikeda, T. M., Ohnishi, N., Nagamine, T., Oda, S., Hisatomi, T., and Yano, H. 2005. Identification of new puroindoline genotypes and their relationship.to flour texture among wheat cultivars. J. Cereal Sci. 41:1-6.

Kammeraad, J. D., Giroux, M. J., Hogg, A. C., and Martin, J. M. 2016. Mutagenesis-derived puroindoline alleles in Triticum aestivum and their impacts on milling and bread quality. Cereal Chem. 93:201-208.

Law, C. N., Young, C. F., Brown, J. W. S., Snape, J. W., and Worland, J. W. 1978. The study of grain protein control in wheat using whole chromosome substitution lines. Pages 483-502 in: Seed Protein Improvement by Nuclear Techniques. International Atomic Energy Agency: Vienna, Austria.

Lebsock, K. L., Noble, W. B., and Sibbitt, L. D. 1967. Registration of Fortuna wheat. Crop Sci. 7:170.

Ma, D., Zhang, Y., Xia, X., Morris, C., and He, Z. 2009. Milling and Chinese raw white noodle qualities of common wheat near isogenic lines differing in puroindoline b alleles. J. Cereal Sci. 50:126-130.

Martin, J. M., Frohberg, R., Morris, C. F., Talbert, L. E., and Giroux, M. J. 2001. Milling and bread baking traits associated with puroindoline sequence type in hard red spring wheat. Crop Sci. 41:228-234.

Martin, J. M., Meyer, F., Morris, C. F., and Giroux, M. J. 2007. Pilot scale milling characteristics of transgenic isolines of a hard wheat overexpressing puroindolines. Crop Sci. 47:497-506.

Massa, A., Morris, C., and Gill, B. 2004. Sequence diversity of puroindolinea, puroindoline-b, and the grain softness protein genes in Aegilops tauschii Coss. Crop Sci. 44:1808-1816.

Mattern, P. J., Morris, R., Schmidt, J. W., and Johnson, V. A. 1973. Location of genes for kernel properties in the wheat cultivar 'Cheyenne' using chromosome substitution lines. Pages 703-707 in: Proceedings of the 4th International Wheat Genetics Symposium. E. R. Sears and L. M. S. Sears, eds. Agricultural Experiment Station, University of Missouri: Columbia, MO.

Morris, C. F., and Bhave, M. 2008. Reconciliation of D-genome puroindoline allele designations with current DNA sequence data. J. Cereal Sci. 48:277-287.

Morris, C. F., Lillemo, M., Simeone, M., Giroux, M., Babb, S., and Kidwell, K. 2001. Prevalence of puroindoline grain hardness genotypes among historically significant North American spring and winter wheats. Crop Sci. 41:218-228.

Morris, C. F., and Rose, S. P. 1996. Wheat. Pages 3-54 in: Cereal Grain Quality. R. J. Henry and P. S. Kettlewell, eds. Chapman and Hall: London, U.K.

Pomeranz, Y. 1987. Modern Cereal Science and Technology. VCH: New York, NY.

Pomeranz, Y., and Williams, R. C. 1990. Wheat hardness: Its genetic, structural, and biochemical background, measurement, and significance. Pages 471-548 in: Advances in Cereal Science and Technology. Y. Pomeranz, ed. Vol. 10. American Association of Cereal Chemists: St. Paul, MN.

Reynolds, N. P., Martin, J. M., and Giroux, M. J. 2010. Increased wheat grain hardness conferred by novel puroindoline haplotypes from Aegilops tauschii. Crop Sci. 50:1718-1727.

Shewry, P. R., and Hey, S. J. 2015. The contribution of wheat to human diet and health. Food Energy Secur. 4:178-202.

Simmonds, D. H. 1974. Chemical basis of hardness and vitreosity in the wheat kernel. Bakers Dig. 48:16-29.

Slade, A. J., Fuerstenberg, S. I., Loeffler, D., Steine, M. N., and Facciotti, D. 2005. A reverse genetic, nontrasgenic approach to wheat crop improvement by TILLING. Nat. Biotechnol. 23:75-81.

Swan, C. G., Meyer, F. D., Hogg, A. C., Martin, J. M., and Giroux, M. J. 2006. Puroindoline $\mathrm{b}$ limits binding of puroindoline a to starch and grain softness. Crop Sci. 46:1656-1665.

Takata, K., Ikeda, T., Yanaka, M., Matsunaka, H., Seki, M., Ishikawa, N., and Yamauchi, H. 2010. Comparison of five puroindoline alleles on grain hardness and flour properties using near isogenic wheat lines. Breed. Sci. 60:228-232.

Tranquilli, G., Heaton, J., Chicaiza, O., and Dubcovsky, J. 2002. Substitutions and deletions of genes related to grain hardness in wheat and their effect on grain texture. Crop Sci. 42:1812-1817.

Wanjugi, H. W., Hogg, A. C., Martin, J. M., and Giroux, M. J. 2007. The role of puroindoline A and B individually and in combination on grain hardness and starch association. Crop Sci. 47:67-76. 